\title{
REPRODUÇÃO SEXUADA EM MUSGOS ACROCÁRPICOS DO ESTADO DE PERNAMBUCO, BRASIL
}

\author{
Sylvia Mota de Oliveira ${ }^{1}$ \\ Kátia Cavalcanti Pôrto ${ }^{1}$
}

\section{Recebido em 28/01/1999. Aceito em 16/04/1999}

\begin{abstract}
RESUMO - (Reprodução sexuada em musgos acrocárpicos do Estado de Pernambuco, Brasil). A freqüência de reprodução sexuada através da produção de esporófito foi determinada para musgos acrocárpicos, coletados no Estado de Pernambuco e depositados no Herbário UFP. Cada exsicata foi observada ao estereomicroscópio para verificação da ocorrência e do estádio de desenvolvimento do esporófito. Às informações obtidas acrescentaram-se dados de coleta e outros específicos pesquisados em literatura. Examinaram-se 770 exsicatas, pertencentes a 11 famílias e 59 espécies. Destas, 26 são monóicas, 27 dióicas e as seis restantes têm sistema reprodutivo desconhecido. A ocorrência de esporófito por amostras foi de $3: 1$, de monóica em relação à dióica. Apresentaram esporófito $88 \%$ das espécies com maior riqueza de amostras, havendo tendência, entre as dióicas, de produção ocasional ou rara de esporófito. A análise do estádio de desenvolvimento dos esporófitos por ocasião da coleta demonstrou que a produção ocorre principalmente durante o período chuvoso. Confirmase então a importância da umidade e da autofecundação na reprodução sexuada destes musgos.
\end{abstract}

Palavras-chave - musgos acrocárpicos, fenologia, esporófito, monóicos, dióicos

\begin{abstract}
Sexual reproduction in acrocarpous mosses of Pernambuco State, Brazil). The frequency of sexual reproduction in acrocarpous mosses collected in Pernambuco State, and subsequently deposited in the UFP Herbarium, was determined based on sporophyte production. Each voucher was observed under a dissecting microscope for recording the presence of the sporophyte and its developmental stage. The data obtained from literature was also registered. 770 voucher, distributed in 11 families and 59 species, were examined. 26 species have a monoecious reproductive system, 27 a dioicous one, and the six remaining ones have an unknown breeding system. The rate of fruiting specimens was higher in monoicous (3:1) than dioicous ones. Sporophytes were found in $88 \%$ of the best represented species. The frequency of fruiting specimens of dioicous species is either occasional or rare. The analysis of the developmental stages of sporophyte throughtout the year demonstrated that the production of sporophytes mainly occurs during the rainy season. Finally, humidity and self-fertilization play an important rule in the sexual reproduction of the acrocarpous mosses.
\end{abstract}

Key words - acrocarpous mosses, phenology, sporophyte, monoicous, dioicous

\section{Introdução}

Levantamentos florísticos sobre briófitas têm servido de base a trabalhos de biologia reprodutiva. Gemmel (1950) quantificou, para os musgos da flora britânica, a

1 Departamento de Botânica, CCB, Universidade Federal de Pernambuco, Av. Prof. Moraes Rego s.n., CEP 50.670-901, Recife, PE, Brasil. e-mail: sylviamota@hotmail.com kporto@npd.ufpe.br 
freqüência de esporófito, associando-a ao sistema reprodutivo da espécie. Este autor observou que $83 \%$ das espécies encontradas comumente com esporófito eram monóicas e ainda, $87 \%$ das espécies cujo esporófito era desconhecido ou raro, eram dióicas. Comportamento semelhante foi constatado por Longton \& Schuster (1983) para os musgos da Guatemala, listados por Bartram, em 1949, nos quais a presença de esporófito foi observada em $97 \%$ das espécies monóicas e $78 \%$ das dióicas. Por sua vez, Rohrer (1982) comparando a composição florística de musgos de duas florestas (seca e úmida) dos Estados Unidos, obteve, em ambas, percentuais superiores a 75\% para produção de esporófito em monóicas e inferiores a $20 \%$ para dióicas.

Na literatura pertinente às briófitas do Brasil, há referências eventuais à presença de esporófito (Pôrto 1990; Yano 1992; Valdevino 1994), porém sem qualquer exploração de sua relação com fatores ambientais ou com o tipo de sistema reprodutivo. Visando iniciar estudos que abordem estas relações, foram examinadas as exsicatas de musgos acrocárpicos (grupo artificial que possui esporófito terminal e, portanto, gametófito com crescimento determinado) do Herbário UFP, da Universidade Federal de Pernambuco. Em parte, as coleções são resultantes de pesquisas sistemáticas, referentes a teses, dissertações e monografias, realizadas com o objetivo de inventariar a brioflora de diversos ecossistemas do Estado de Pernambuco.

Portanto, esta pesquisa teve por finalidade testar algumas hipóteses referentes à ocorrência de reprodução sexuada em musgos acrocárpicos, através da análise da frequiência da produção de esporófitos em relação ao seu sistema reprodutivo e à sazonalidade da região.

\section{Material e métodos}

Selecionaram-se exsicatas de musgos acrocárpicos coletados no Estado de Pernambuco e depositadas no Herbário UFP. Em fichas elaboradas especificamente para esta pesquisa, cadastrou-se cada exsicata, compilando os dados de coleta; informaçōes específicas pesquisadas em literatura, sobretudo referentes ao sistema reprodutivo; e observações efetuadas ao estereomicroscópio, relativas à presença e estádio de maturação dos esporófitos (imaturo, maduro indeiscente e maduro deiscente).

Para a análise da distribuição das amostras por sistema reprodutivo e fase de desenvolvimento dos esporófitos considerou-se o universo de amostras examinado, enquanto para o cálculo da freqüência de amostras férteis e estéreis consideraram-se apenas as espécies com número de exsicatas superior a 15. As classes de freqüência estabelecidas para a ocorrência de esporófito correspondem às seguintes faixas de valores: comum $=60-100 \%$, ocasional $=20-59 \%$ e, nula a rara $=0-19 \%$ do total de exsicatas por espécie. A terminologia taxonômica foi atualizada utilizando-se bibliografia de referência (Sharp et al. 1994; Delgadillo et al. 1995).

\section{Resultados}

Examinaram-se 770 exsicatas de musgos acrocárpicos cadastradas no Herbário UFP. Este acervo é composto por 11 famílias e 59 espécies. Destas, 26 são monóicas, 27 dióicas, e as seis restantes têm sistema reprodutivo (oicia) desconhecido, ou seja, não referido na literatura disponível (Tab. 1). 
Tabela 1. Sinopse das espécies e respectivo sistema reprodutivo de musgos acrocárpicos do Estado de Pernambuco, Brasil ( $\mathrm{D}=$ Dióico; $\mathrm{M}=$ Monóico; $\mathrm{NR}=$ não referido).

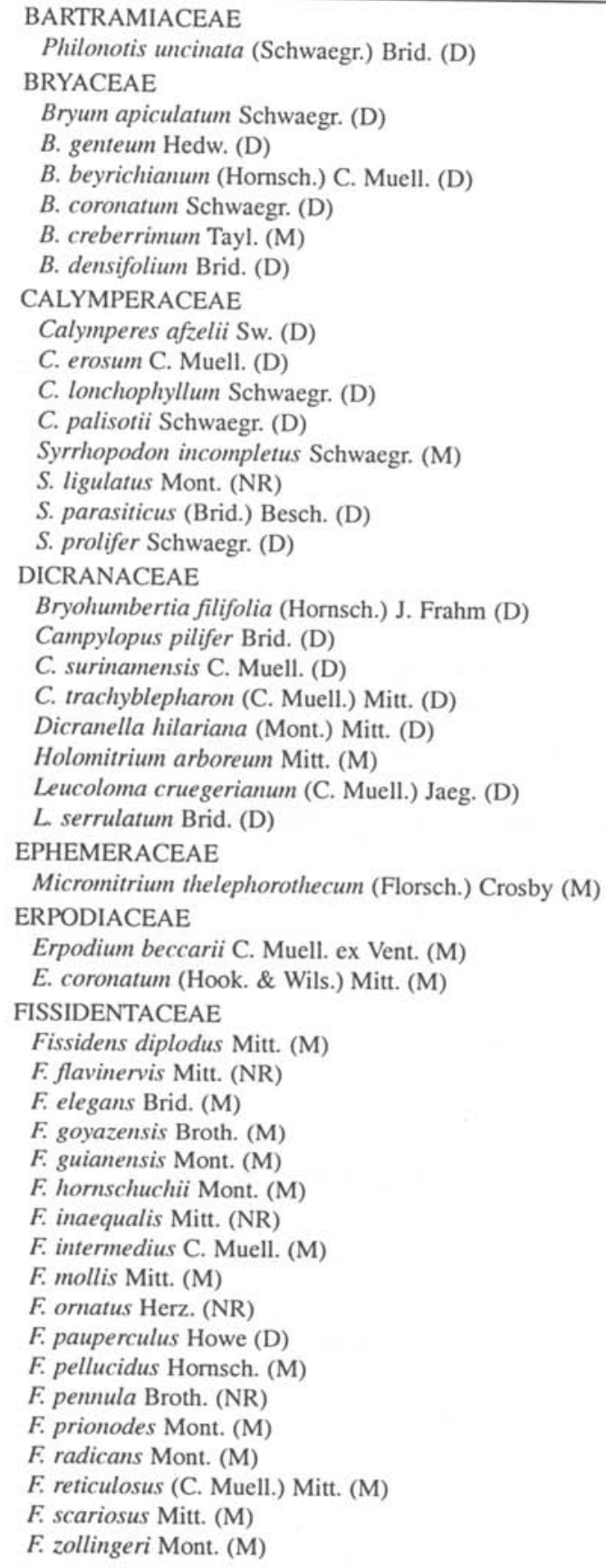


Tabela 1. (continuação) Sinopse das espécies e respectivo sistema reprodutivo de musgos acrocárpicos do Estado de Pernambuco, Brasil ( $\mathrm{D}=$ Dióico; $\mathrm{M}$ = Monóico; $\mathrm{NR}=$ não referido).

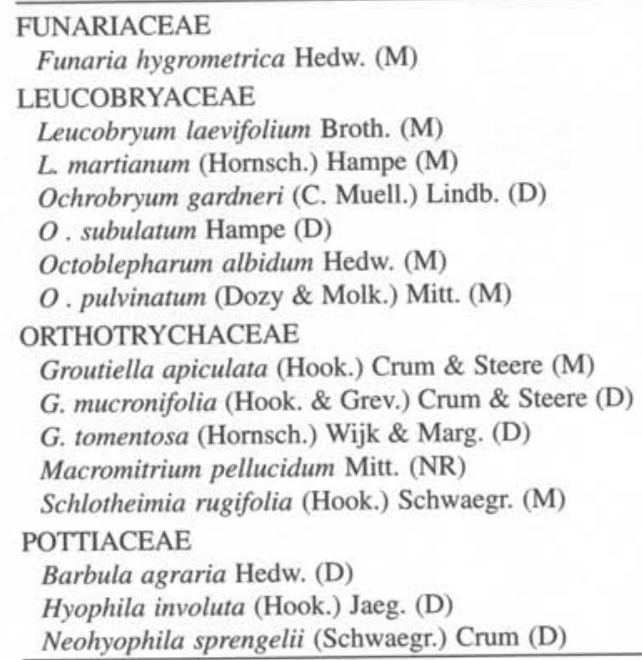

As exsicatas examinadas são, em sua maioria, provenientes dos seguintes ecossistemas: Floresta Atlântica - remanescentes de mata úmida costeira, desde o nível do mar até baixa altitude, em diversos estádios de conservação; Brejos de Altitude matas plúvio-nebular de altitude moderada, entre 600 e $1100 \mathrm{~m}$, enclavadas na região semi-árida; e Caatinga hipo- e hiperxerófila. As exsicatas restantes foram coletadas em jardins e praças de área urbana (Fig. 1).

Considerando o acervo estudado, a presença de esporófito foi observada em cerca de $60 \%$ do total das exsicatas de espécies monóicas e em apenas 20\% das dióicas. Esta proporção se mantém semelhante nos três ecossistemas mencionados anteriormente (Fig. 2).

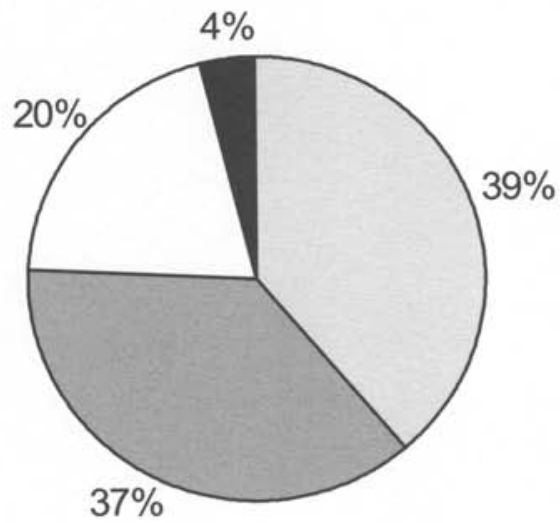

Floresta Atlântica Costeira

Brejo de Altitude

Caatinga

Outros

Figura 1. Distribuição por habitat das amostras de musgos acrocárpicos do Estado de Pernambuco, Brasil. 


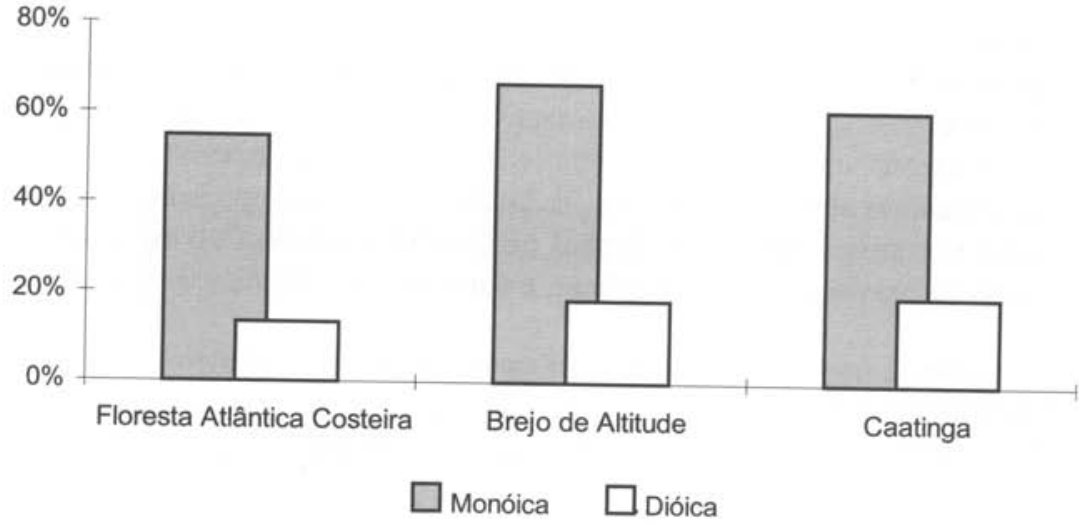

Figura 2. Frequêencia das amostras de musgos acrocárpicos por sistema reprodutivo do nos três principais ecossistemas do Estado de Pernambuco, Brasil.

Para a análise da freqüência de produção de esporófito consideraram-se apenas as espécies com maior representatividade em exsicatas $(>15)$. A maior proporção de exsicatas férteis foi mais uma vez observada para as espécies com sistema reprodutivo monóico, em proporção de aproximadamente 2:1, em relação àquelas com sistema reprodutivo dióico (Tab. 2).

Tabela 2. Ocorrência de esporófito em espécies (>15 exsicatas) de musgos acrocárpicos do Estado de Pernambuco, Brasil.

\begin{tabular}{lccc}
\hline Sistema reprodutivo/Espécie & Total de exsicatas & Amostras férteis & \% Amostras férteis \\
\hline Monóico & 72 & & \\
Octoblepharum albidum & 40 & 48 & 66,7 \\
F. pennula & 33 & 14 & 7,5 \\
F. reticulosus & 26 & 0 & 42,4 \\
Syrrhopodon incompletus & 24 & 14 & 0 \\
F. guianensis & 19 & 14 & 58,3 \\
Schlotheimia rugifolia & 17 & 14 & 73,7 \\
F. diplodus & 231 & 107 & 82,3 \\
Total & & & 46,3 \\
\hline Dióico & 76 & 3 & 3,9 \\
Syrrhopodon prolifer & 62 & 20 & 32,2 \\
Barbula agraria & 39 & 1 & 2,6 \\
Syrrhopodon parasiticus & 31 & 11 & 35,5 \\
Calymperes palisotii & 25 & 1 & 4 \\
Leucoloma serrulatum & 24 & 5 & 20,8 \\
Bryum argenteum & 18 & 7 & 38,9 \\
B. coronatum & 17 & 7 & 41,2 \\
B. densifolium & 16 & 0 & 0 \\
C. afzelii & 16 & 10 & 2,5 \\
Groutiella mucronifolia & 324 & 65 & 20,1 \\
\hline Total & & & \\
\hline
\end{tabular}


Além disso, constatou-se que a reprodução sexuada, mesmo que pouco freqüente em alguns táxons, foi registrada para $88 \%$ das espécies examinadas. A distribuição das espécies em classes de freqüência de exsicatas férteis demonstrou, apenas para espécies dióicas, uma tendência a maior representatividade em determinadas classes, sendo estas as de freqüência ocasional e rara (Tab. 3). Duas espécies não apresentaram esporófito em nenhuma amostra observada. Ambas pertencem à família Calymperaceae, sendo uma monóica, Syrrhopodon incompletus, e outra dióica, Calymperes afzelli.

Tabela 3. Classes de frequiência de esporófito nas espécies de musgos acrocárpicos (> 15 exsicatas) do Estado de Pernambuco, Brasil.

\begin{tabular}{lccc}
\hline Sistema reprodutivo & Comum & Ocasional & Rara/nula \\
\hline Monóica & 3 & 2 & 2 \\
Dióica & 1 & 5 & 4 \\
\hline Total & 4 & 7 & 6 \\
\hline
\end{tabular}

A ocorrência dos estádios de desenvolvimento dos esporófitos ao longo dos meses do ano permitiu análise da tendência do período de produção dos mesmos (Fig. 3a-c). A presença de esporófitos imaturos, em fase inicial de desenvolvimento, foi mais expressiva nos meses de maio a setembro, que na maioria dos municípios amostrados, correspondem ao período chuvoso (Fig. 3a). Esporófitos na fase seguinte, ou seja, maduros indeiscentes, foram observados com maior freqüência a partir de agosto (Fig. $3 \mathrm{~b}$ ), enquanto que esporófitos deiscentes não predominaram em um determinado período no ano (Fig. 3c).

\section{Discussão}

Com base no acervo examinado, há maior freqüência de esporófitos em espécies monóicas, fato largamente aceito na literatura pertinente (Longton \& Schuster 1983; Longton 1990). Essa tendência se repete nos três ecossistemas melhor explorados e pode ser interpretada como consequiência da maior proximidade entre os gametângios nos ramos de espécies monóicas, o que facilita, independentemente do habitat, a fecundação para posterior crescimento do esporófito.

É válido salientar que nas três linhas evolutivas de Bryophyta, de modo geral, a condição dióica é considerada primitiva (Longton \& Schuster 1983). Nas espécies monóicas, a autofecundação, embora não favorecendo a variabilidade gênica, é uma garantia à própria reprodução sexuada, haja visto que nessas plantas há necessidade de água para o transporte do anterozóide até a oosfera. Briófitas com sistema reprodutivo dióico podem ter comprometida a reprodução pela distância das populações femininas e masculinas, associada ao problema da maturação nem sempre sincrônica dos gametângios.

Longton (1990) relata o abandono da reprodução sexuada em espécies dióicas de regiões polares e altas latitudes de regiões temperadas. Para os musgos acrocárpicos estudados, apesar das espécies dióicas apresentarem freqüência de esporófito mais baixa que as monóicas, não há abandono da reprodução sexuada. As duas espécies que não apresentaram esporófito pertencem a Calymperaceae, família caracterizada pela presença 
A

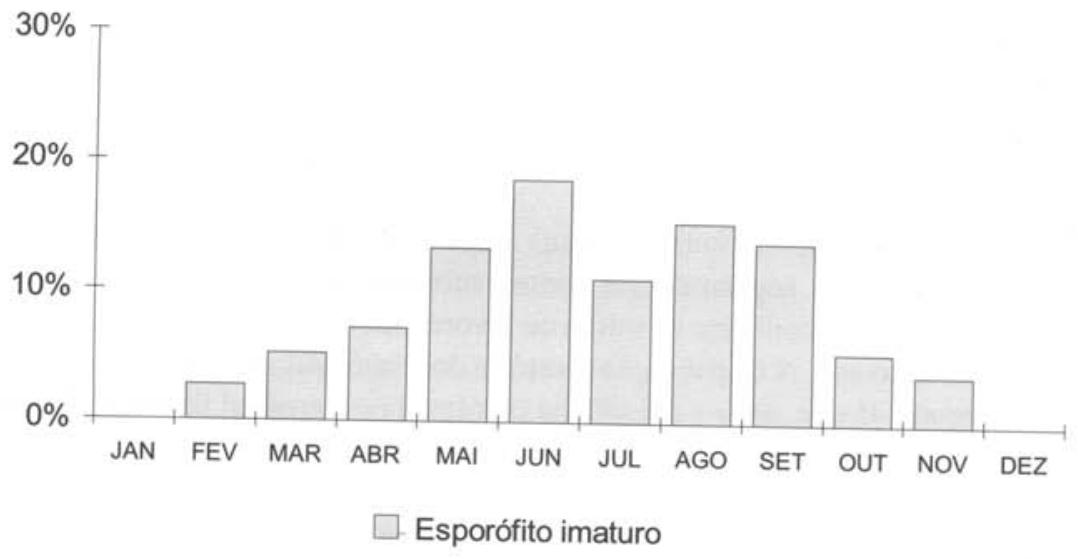

B

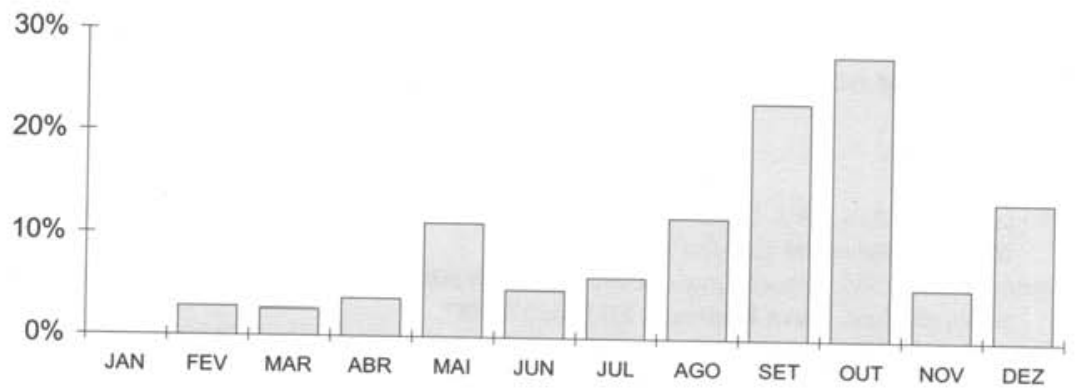

$\square$ Esporófito maduro indeiscente

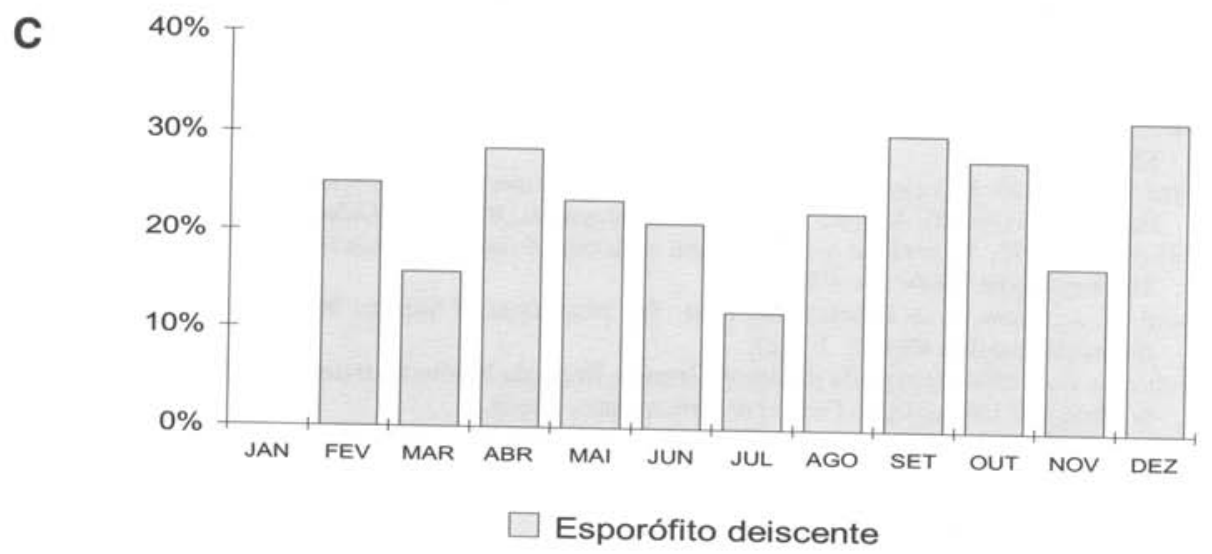
Figura 3A-C. Distribuição mensal das fases de desenvolvimento dos esporófitos de musgos acrocárpicos
do Estado de Pernambuco, Brasil. 
freqüente de gemas em seus filídios. $\mathrm{Na}$ grande maioria das espécies da família a reprodução sexuada e a formação de esporófitos é rara (Sharp et al. 1994).

A reprodução sexuada em briófitas de regiões tropicais apresenta sazonalidade, concentrando-se basicamente nos meses da estação chuvosa, como observado por diversos autores (Egunyomi 1979; Odu 1982; Moyá 1992). A concentração de esporófitos imaturos durante os meses da estação chuvosa e de esporófitos maduros indeiscentes (fase seguinte) nos meses subseqüentes, sugerindo continuidade no desenvolvimento, confirma o padrão de favorecimento da reprodução sexuada durante o período chuvoso. A distribuição aleatória dos esporófitos deiscentes ao longo do ano era esperada, já que, após a deiscência da cápsula e a gradual liberação dos esporos, o esporófito continua preso ao gametófito por tempo indeterminado.

A reprodução sexuada, caracterizada pela presença de esporófito, foi constatada na maior parte das espécies monóicas e dióicas de musgos acrocárpicos ocorrentes em Pernambuco. A monoicia, em termos gerais, favorece a produção de esporófitos e, em musgos acrocárpicos, esta produção se dá com maior intensidade nos meses do período chuvoso. Confirma-se assim a importância da autofecundação e da disponibilidade hídrica na produção de esporófitos nos musgos ocorrentes nos diversos ecossistemas de Pernambuco.

\section{Referências}

Delgadillo, C.; Bello, B \& Cárdenas, A . 1995. Latmoss, a catalogue of Neotropical mosses. Annals of the Missouri Botanical Garden 56: 1-191.

Egunyomi, A. 1979. Autoecology of Octoblepharum albidum Hedw. in Western Nigeria II. Phenology and water relations. Nova Hedwigia 31(1/2): 377-387.

Gemmel, A. R. 1950. Studies in the Bryophyta. I. The influence of sexual mechanisms on varietal production and distribution of British Musci. New Phytologist 49: 64-71,

Longton, R. E. \& Schuster, R. M. 1983. Reproductive biology. In: New manual of Bryology. R. M. Schuster (Ed.), Journal of the Hattori Botanical Laboratory, Nichinan.

Longton, R. E. 1990. Sexual reproduction in bryophytes in relation to physical factors of the environment Pp. 139-146. In: R. N. Chopra \& S. C. Bhatla (Ed.), Bryophytes development, physiology and biochemistry. CRC Press, Boca Raton.

Moyá, M. T. 1992. Phenological observations and sex ratios in Marchantia chenopoda L. (Hepaticae: Marchantiaceae).Tropical Bryology 6: 161-168.

Odu, E. A. 1982. Phenology of west tropical african mosses. Journal of the Hattori Botanical Laboratory 52: 283-285.

Pôrto, K. C. 1990. Bryoflores d'une forêt de plaine et d'une forêt d'altitude moyenne dans l'Etat de Pernambuco (Brésil). Analyse floristique. Cryptogamie, Bryologie Lichénologie 13(3): 187-219.

Rohrer, J. R. 1982. Sporophyte production and sexuality of mosses on two Northern Michigan habitats. The Bryologist 85(4): 394-400.

Sharp, A. J.; Crum, H. \& Eckel, P. M. 1994. The moss flora of Mexico. Memoirs of the New York Botanical Garden 69(1-2): 1-1113.

Valdevino, J. A. 1994. Bryopsida do Bituri Grande, Brejo da Madre de Deus - PE (Brasil). Dissertação de Mestrado. Universidade Federal de Pernambuco, Recife.

Yano, O. 1982. Leucobryaceae (Bryopsida) do Brasil. Tese de Doutorado. Universidade de São Paulo, São Paulo. 